\title{
Numerical Simulation of Lateral Jet Interaction
}

\author{
Jin Chen, Yaofeng Liu, Jinglong Bo \\ China Academy of Aerospace Aerodynamics, Beijing, China \\ Email: jsxyczq@hotmail.com
}

How to cite this paper: Chen, J., Liu, Y.F. and Bo, J.L. (2017) Numerical Simulation of Lateral Jet Interaction. Journal of Applied Mathematics and Physics, 5, 1686-1693. https://doi.org/10.4236/jamp.2017.59141

Received: July 9, 2017

Accepted: September 12, 2017

Published: September 15, 2017

\begin{abstract}
Jet interaction effects on aerodynamic characteristics of aircraft in subsonic/transonic compressible crossflow are investigated numerically. The high reliable CFD method is established and compared with existing experimental results. The lateral jet interaction characteristics of lateral jet in subsonic/ transonic compressible crossflow on an ogive-cylinder configuration are simulated numerically. Variation characteristics of normal force amplification factor, pitching moment and amplification factor are analyzed and compared with the results at supersonic condition. Research results and some useful conclusions can be provided for the design of RCS aircraft control system as basis and reference in subsonic/transonic compressible crossflow.
\end{abstract}

\section{Keywords}

Lateral Jet, Jet Interaction, Shock Wave/Boundary Layer Interaction, Numerical Simulation

\section{Introduction}

Direct force induced by Reverse Control System (RCS) lateral jet can supplement the ability of control system as well as improve maneuvering and rapid response ability. This technology has been utilized successfully in multiple aircrafts, such as airship, space shuttle, interceptor et al. The requirements and feature of future air fights demand of the new generation air-to-air missile have the ability of rapid response and all-around attacking skills to attack high maneuvering targets, where RCS technology is effective to be used.

The complex flowfield interaction of RCS lateral jet and outflow, containing complex wave and eddy structures, not only induces extra interaction force and moment but also influences total aerodynamics characteristics and helm efficiency. The influence to aerodynamics characteristics is strongly affected by factors like flight environment, attitude et al. The changing process is highly nonli- 
near. It is important to accurately predict the jet interaction influence at different conditions for the application of RCS.

The velocity scope of air-to-air missile using RCS ranges from subsonic, transonic to supersonic conditions. In former research, the emphasis was supersonic/hypersonic condition [1]-[17] while few research [4] [12] has been carried out for subsonic/transonic condition (including simulation and experiments). The existing method and mechanism that we have achieved is far from the requirements in designing of aircrafts using RCS at subsonic/transonic condition.

\section{Numerical Simulation Method}

\subsection{Discretization Method}

The three-dimensional compressible Reynolds Averaged Navier-Stokes equation is applied as governing equation. The discretization process is carried out with finite volume method. Convection terms are discretized with second-order Roe algorithms. Standard second-order accurate central differences are used for the viscous terms. Temporal discretization is utilized with LU-SGS implicit method. One-equation Spalart-Allmaras model is used as turbulent model. A local time-step procedure is utilized to accelerate convergence of the solution to steady state.

\subsection{Boundary Condition}

1) Inflow Boundary: Inflow is supersonic or hypersonic. The downstream flowfield does not affect the upper-stream flowfield. The static pressure, static temperature and Mach number of inflow is given at inlet boundary.

2) Outflow Boundary: When outflow is supersonic, the downstream flowfield does not affect the upper-stream flowfield. All parameters can be numerically extrapolated.

3) Wall Boundary: Wall uses adiabatic no-slip condition.

4) Symmetry Boundary: In the symmetry plane, normal velocity is zero and all normal gradients of variable parameters are zero.

5) Jet Boundary: The parameters are used at nozzle outlets.

6) Farfield Boundary: Using no-reflect boundary.

\subsection{Method Verification}

The numerical simulation methods established has been verified and compared with a large number of jet interaction experimental results [9] [10] [11]. In this paper, numerical simulation and experiment of the lateral jet interaction flowfield at after body of typical cone-pillar revolution body have been utilized. The model configuration and computational condition can be referred to relative papers [12]. Figure 1 shows the configuration of case. Figure 2 shows the comparison of numerical results and experiment results about pressure distributions $\left(\mathrm{P} / \mathrm{P}_{\infty}\right)$ at symmetry line in front of the nozzle exit at $\mathrm{M}_{\infty}=0.69$ and 0.91 . In Figure 2, jet on means existing jet interaction, while jet off means no jet interaction, 
from which we can easily conclude that the numerical results are consistent with the experimental results. The error between numerical results and experiments is less than 5 percent, which means the numerical simulation methods established are reliable and feasible.

\section{Numerical Model and Parameters}

The numerical model and coordinate system is shown as Figure 3. The configuration is cone-pillar revolution body [4]. D is defined as the bottom diameter of the model while $\mathrm{L}$ is defined as the total length of the model $(\mathrm{L} / \mathrm{D}=10)$ is the circumference angle and the meridian line of $\phi=0^{\circ}$ is located at the symmetry plane of the model where the center of the nozzle is crossed. The supersonic nozzle is located at $4.25 \mathrm{D}$ and the diameter of the exit $\mathrm{D}_{\mathrm{J}}=0.1429 \mathrm{D}$.

The rectangular coordinate system is used and the origin point is located at the head peak of the model. Since the flowfield is symmetric, half of the flowfield is simulated. Axial of $\mathrm{x}$ is along with the flow direction while axial of $\mathrm{z}$ is vertical to the symmetry plane. Air is used as medium both for freestream and jet flow. The simulation parameter is given followed with the flight condition and listed as Table 1 .

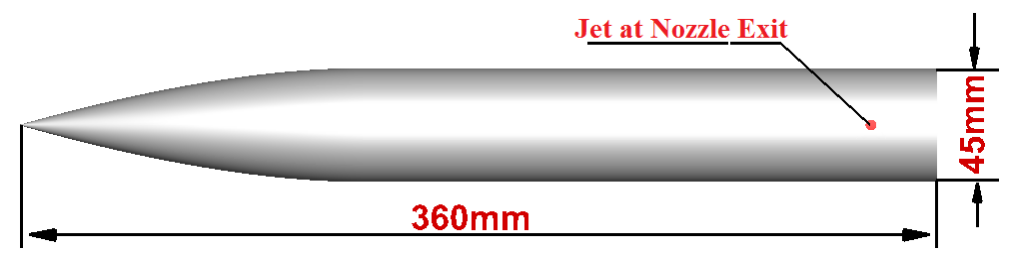

Figure 1. Configuration of case.

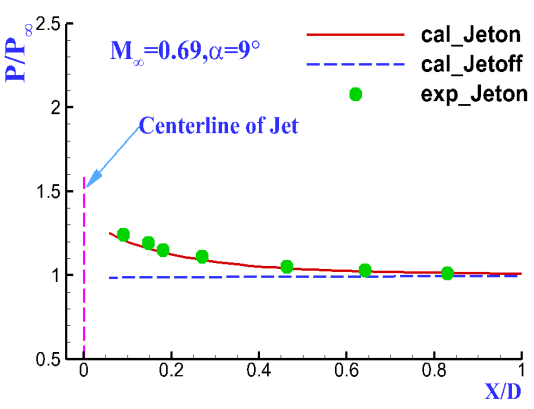

(a)

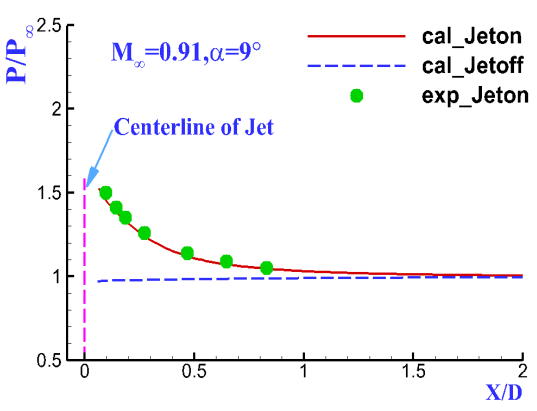

(b)

Figure 2. Pressure distribution about numerical results and experimental results at symmetry line in front of the nozzle exit $\left(\alpha=9^{\circ}\right)$; (a) $\mathrm{M}_{\infty}=0.69$; (b) $\mathrm{M}_{\infty}=0.91$.

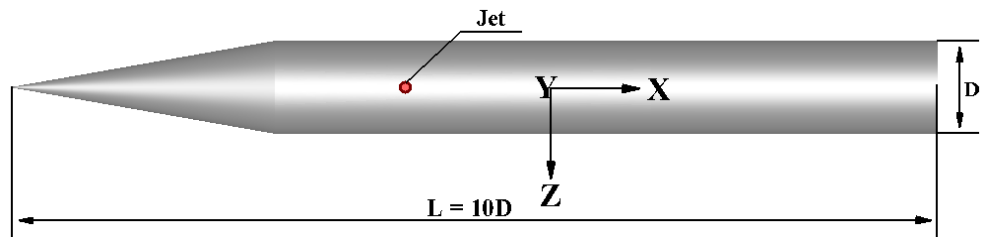

Figure 3. Numerical model and coordinate system. 
Table 1. Simulation parameter.

\begin{tabular}{cccc}
\hline $\begin{array}{c}\text { Freestream Mach } \\
\text { number }\end{array}$ & $\begin{array}{c}\text { Pressure distribution } \\
\mathrm{P} \mathrm{P}_{\infty}\end{array}$ & $\begin{array}{c}\text { Attack angle } \\
\alpha\left({ }^{\circ}\right)\end{array}$ & $\begin{array}{c}\text { Jet flow Mach } \\
\text { number }\end{array}$ \\
\hline $0.6,0.9,1.1,1.5,2.0$ & 2.1 & $-10,-5,0,5,10$ & 2.8 \\
\hline
\end{tabular}

\section{Results and Discussion}

The numerical simulation of the subsonic, transonic and low supersonic jet interaction flowfield from $\alpha=-10^{\circ} \sim 10^{\circ}$ and $\mathrm{M}_{\infty}=0.6 \sim 2.0$ is completed using the numerical methods above. The calculation grid is established based on multi-block patched grid technique. Figure 4 shows the grid of the wall and symmetry plane. The local grid of the nozzle exit is shown in the figure as well. Grid is compacted at the joint of cone-pillar and the nozzle. The total number of the grid is approximately $6,000,000$.

\subsection{Interaction Flowfield}

The cloud pictures of pressure about wall surface and symmetry plane at $\mathrm{M}_{\infty}=$ $0.6,0.9 、 1.1,1.5,2.0, \mathrm{H}=0 \mathrm{~km}, \alpha=0^{\circ}$ when the jet is on are separately shown in Figure 5 and Figure 6. When $\mathrm{M}_{\infty}=0.6$, the compress wave is appeared in front of the jet and the pressure is raised. When $\mathrm{M}_{\infty}=0.9$, the compress wave is strengthened and the pressure is raised further on where some shock wave appears. When $M_{\infty} \geq 1.1$, the separate shock and bow shock which are located at upper stream of the nozzle as well as the strong expand region which is close to the downstream of the nozzle followed with the rising pressure region can be seen in the figure. The separate region is reduced and the strength of shock wave is increased along with the rising Mach number.

\subsection{Effect of Jet Interaction in Aerodynamics}

Both Normal force amplification factor and pitching moment amplification factor are used to describe the effect of RCS jet interaction about aerodynamics of the aircrafts. The definition is listed below.

Mathematical formula of Normal force amplification factor $\mathrm{K}_{\mathrm{y}}$ is

$$
K_{y}=\frac{F_{\text {jeton }}-F_{\text {jetoff }}}{F_{\text {jet }}}
$$

Mathematical formula of pitching moment amplification factor $\mathrm{K}_{\mathrm{Mz}}$ is

$$
K_{M z}=\frac{M_{z, \text { jeton }}-M_{z, \text { jetoff }}}{M_{z, \text { jet }}}
$$

Figure 7 shows the changing rules of $\mathrm{K}_{\mathrm{y}}$ which is induced by lateral jet interaction from $\mathrm{M}_{\infty}=0.6 \sim 2.0, \mathrm{H}=0 \mathrm{~km}, \alpha=-10^{\circ} \sim 10^{\circ}$. All $\mathrm{K}_{\mathrm{y}}$ is less than 1.0 which means a negative effect induced by jet interaction from the figure. $\mathrm{K}_{\mathrm{y}}$ is decreased when the attack angle is increased. The range ability is increased along with the rising Mach number as well. $\mathrm{K}_{\mathrm{y}}$ is increased at first and decreased afterwards along with the attack angle when Mach number is 2.0. 


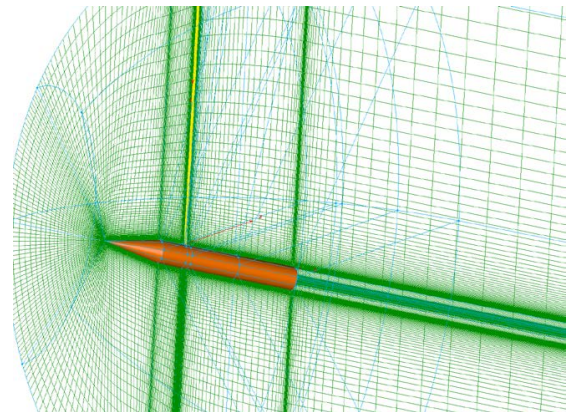

(a)

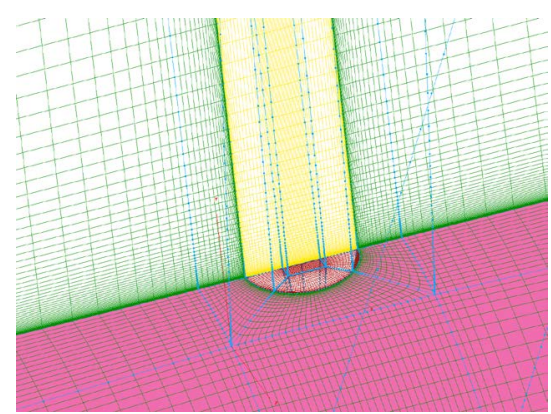

(b)

Figure 4. Simulation grid. (a) Wall and symmetry plane grid; (b) Local grid around jet exit.

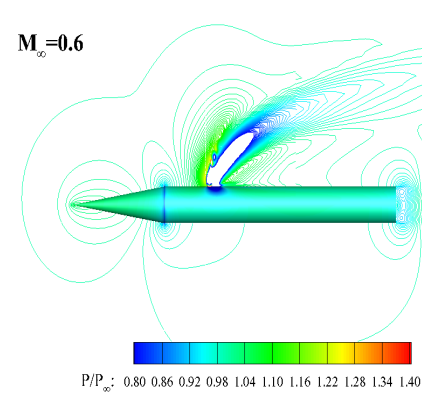

(a)

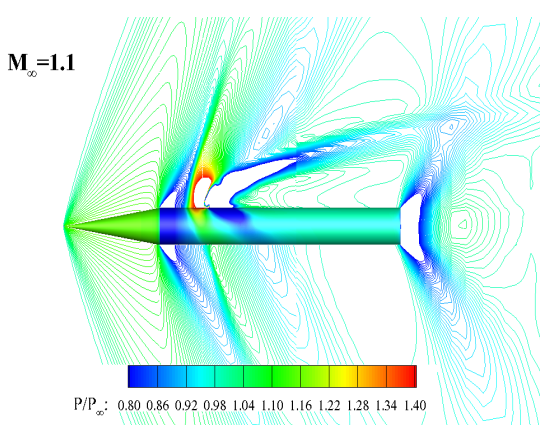

(c)

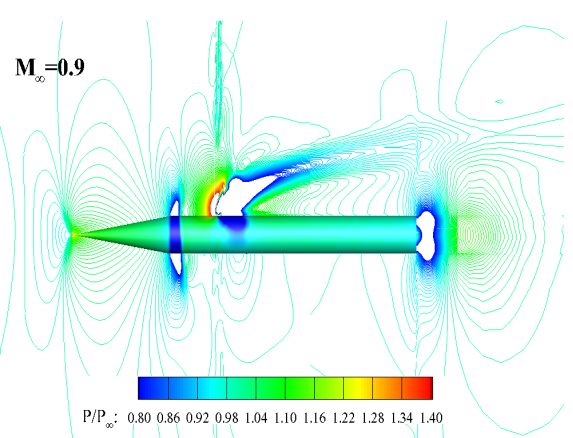

(b)

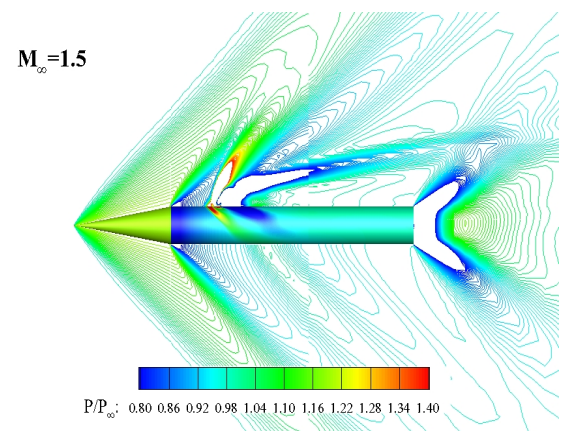

(d)

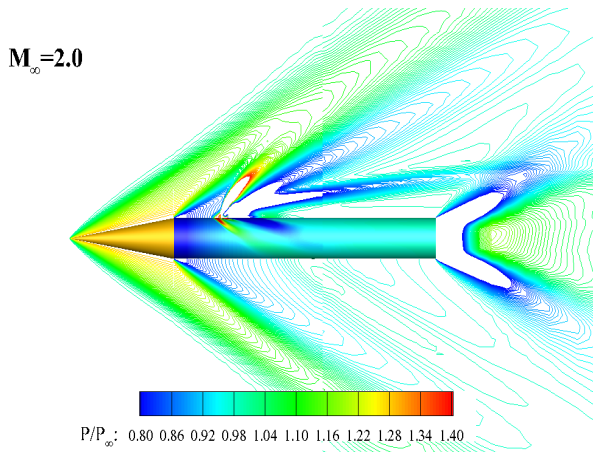

(e)

Figure 5. Wall and symmetry plane pressure cloud pictures $\left(\alpha=0^{\circ}, \mathrm{H}=0 \mathrm{~km}\right) .(\mathrm{a}) \mathrm{M}_{\infty}=$ $0.6, \mathrm{H}=0 \mathrm{~km}, \alpha=0^{\circ}$; (b) $\mathrm{M}_{\infty}=0.9, \mathrm{H}=0 \mathrm{~km}, \alpha=0^{\circ}$; (c) $\mathrm{M}_{\infty}=1.1, \mathrm{H}=0 \mathrm{~km}, \alpha=0^{\circ}$; (d) $\mathrm{M}_{\infty}=1.5, \mathrm{H}=0 \mathrm{~km}, \alpha=0^{\circ}$; (e) $\mathrm{M}_{\infty}=2.0, \mathrm{H}=0 \mathrm{~km}, \alpha=0^{\circ}$. 
Figure 8 shows the changing rules of $\mathrm{K}_{\mathrm{Mz}}$ which is induced by lateral jet interaction from $\mathrm{M}_{\infty}=0.6 \sim 2.0, \mathrm{H}=0 \mathrm{~km}, \alpha=-10^{\circ} \mathrm{b} \sim 10^{\circ}$.

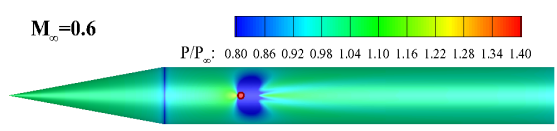

(a)

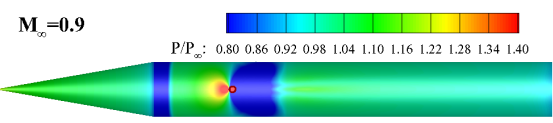

(b)

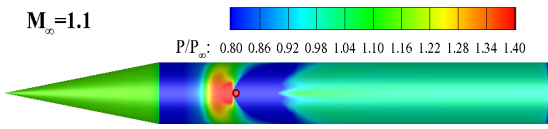

(c)

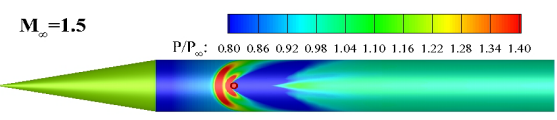

(d)

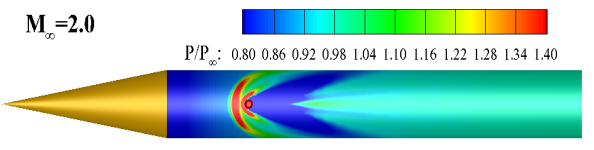

(e)

Figure 6. Wall surface pressure cloud pictures $\left(\alpha=0^{\circ}, \mathrm{H}=0 \mathrm{~km}\right)$. (a) $\mathrm{M}_{\infty}=0.6, \mathrm{H}=0 \mathrm{~km}$, $\alpha=0^{\circ}$; (b) $\mathrm{M}_{\infty}=0.9, \mathrm{H}=0 \mathrm{~km}, \alpha=0^{\circ}$; (c) $\mathrm{M}_{\infty}=1.1, \mathrm{H}=0 \mathrm{~km}, \alpha=0^{\circ}$; (d) $\mathrm{M}_{\infty}=1.5, \mathrm{H}=$ $0 \mathrm{~km}, \alpha=0^{\circ}$; (e) $\mathrm{M}_{\infty}=2.0, \mathrm{H}=0 \mathrm{~km}, \alpha=0^{\circ}$.

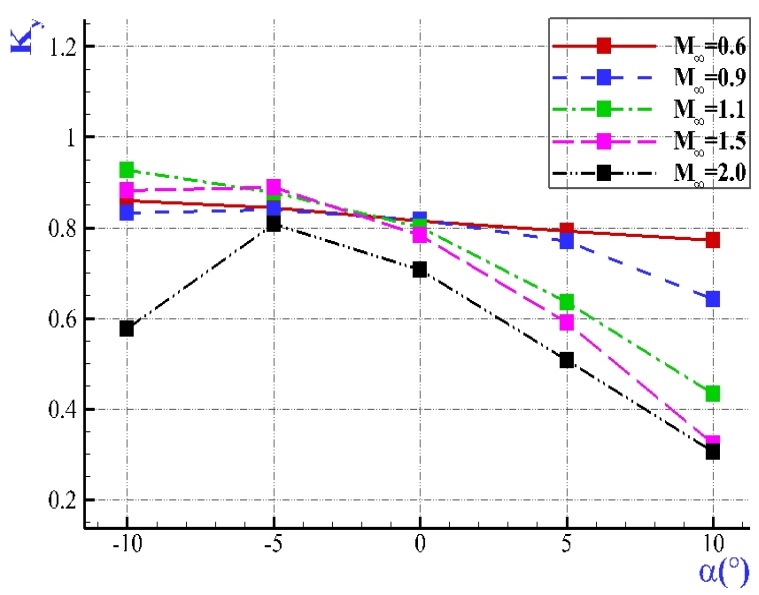

Figure 7. Normal force amplification factor.

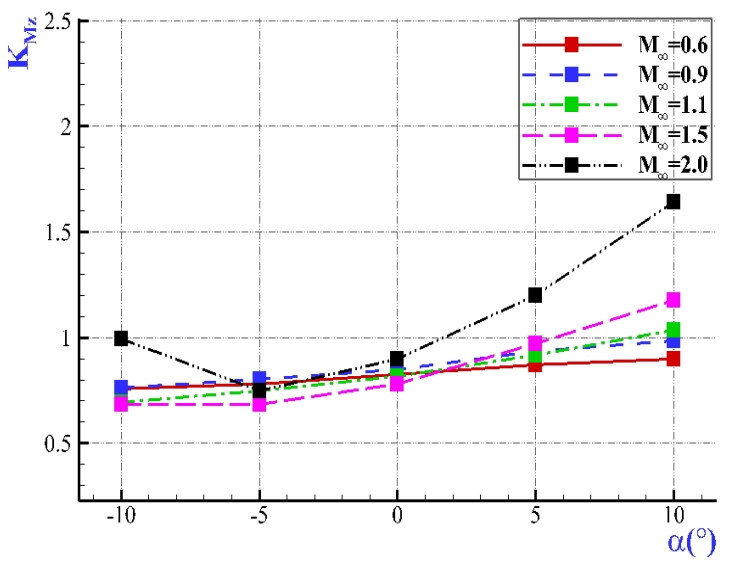

Figure 8. Pitching moment amplification factor. 


\section{Conclusions}

Jet interaction characteristics of cone-pillar revolution body at subsonic and transonic conditions are studied with numerical simulation in this paper. The results can be summarized as below.

1) The numerical methods used in this paper can be accurately enough to simulate the wave and eddy structure in lateral jet interaction flowfield. Main structures of the lateral jet interaction flowfield are shown at subsonic, transonic and low supersonic conditions including jet bow shock, separate shock, $\lambda$-shape shock and so on.

2) All normal force amplification factor is less than 1.0 and complex changes with angle. The amplification factor is decreasing when attack angle is increasing at subsonic and transonic conditions while the amplification factor is increasing at first and decreasing afterwards when attack angle is increasing at supersonic condition.

3) The effect of lateral jet interaction on aerodynamics at subsonic and transonic conditions changes sensitively according to the change of flight parameters. Further study about more parameters should be carried out in the future.

\section{References}

[1] Dash, S.M., Perrell, E.R., Arunajatesan, S., et al. (2001) Simulation of High Speed Jet Interactions in Complex Aeroacoustic Environments. AIAA 2001-2245.

[2] Kennedy, K., Walker, B. and Mikkeisen, C. (1999) Jet Interaction Effects on a Missile with Aerodynamic Control Surfaces. AIAA 1999-0807.

[3] Srivastava, B. (1999) Asymmetric Divert Jet Performance of a Supersonic Missile: Computational and Experimental Comparisons. Journal of Spacecraft and Rocket, 36, 621-632. https://doi.org/10.2514/2.3490

[4] Spaid, F.W. and Cassel, L.A. Aerodynamic Interference Induced by Reaction Controls. AGARD-AG-173.

[5] Stallings Jr., R.L., Lamb, M. and Watson, C.B. Effect of Reynolds Number on Stability Characteristics of a Cruciform Wing-Body at Supersonic Speeds. NASA Technical Paper 1683.

[6] Holden, M., Parker, R., et al. (2000) Hypersonic Testing in the LENS Facility for Lateral Jet Induced Interactions. AIAA 2000-2038.

[7] Graham, M.J., Weinacht, P., Brandeis, J. and Angelini, R. (2000) A Numerical Investigation of Supersonic Jet Interaction for Finned Bodies. AIAA 2000-0768.

[8] Price, B.B., Elliott, G.S. and Ogot, M. (1998) Experimental Optimization of Transverse Jet Injector Geometries for Mixing into a Supersonic Flow. AIAA 1998-3019.

[9] Liu, Y.F., Li, S.X., Ni, Z.Y. and Wang, J.Q. (2007) Numerical Visualization of Lateral Jet Interaction Flowfields. The 9 th Asian Symposium on Visualization, Hong Kong.

[10] Wang, J.Q., Li, S.X. and Sun, M. (2006) Numerical Simulation of Supersonic Lateral Jet Interaction Turbulent Flowfields. Acta Aerodynamica Sinica, 24, 403-409.

[11] Liu, Y.F., Li, S.X. and Ni, Z.Y. (2009) Effects of Multiple Jets Aerodynamic Interaction. Application and Developments of CFD in Large Airbus. Shanghai Jiaotong University Press.

[12] Seginer, A. (1983) Interaction of Multiple Supersonic Jets with a Transonic Flow 
Field. AIAA 1983-1680.

[13] Hsieh, T. (1998) Computation and Analysis of Cross Jet Interaction Flowfields of a Biconic Body at Incidences. AIAA 1998-2625.

[14] Li, S.X. and Ni, Z.Y. (2003) Free Jet Flow and Interacted Jet Flow. The 7 th Asian Symposium on Visualization, Singapore.

[15] Brandeis, J. and Gill, J. (1998) Experimental Investigation of Super- and Hypersonic Jet Interaction on Missile Configurations. Journal of Spacecraft and Rockets, 35, 296-302. https://doi.org/10.2514/2.3354

[16] Keener, E.R. and Chapman, G.T. (1977) Side Forces on a Tangent Ogive Forebody with a Fineness Ratio of 3.5 at High Angles of Attack and Mach Numbers from 0.1 to $0.7 . N A S A T M X-3437$.

[17] Lamont, P.J. Pressure Measurements on an Ogive-Cylinder at High Angles of Attack with Laminar, Transitional, or Turbulent Separation. AIAA 80-1556.

Submit or recommend next manuscript to SCIRP and we will provide best service for you:

Accepting pre-submission inquiries through Email, Facebook, LinkedIn, Twitter, etc. A wide selection of journals (inclusive of 9 subjects, more than 200 journals) Providing 24-hour high-quality service User-friendly online submission system Fair and swift peer-review system Efficient typesetting and proofreading procedure Display of the result of downloads and visits, as well as the number of cited articles Maximum dissemination of your research work

Submit your manuscript at: http://papersubmission.scirp.org/ Or contact jamp@scirp.org 